heading "World: Atlas: Modern," p. 449I, where will be found probably the most complete list of Mercator's atlases extant, ranging from 1495 to 1636 .

AT the meeting of the Geographical Society of Paris on the 6 th instant, M. Germain, who presided, pronounced a eulogium on Milne-Edwards. M. Duveyrier called attention to a report addressed to the Spanish Government by Capt. Bonelli, relative to the Spanish possessions on the West Coast of Africa, according to which it appeared that the writer claimed on behalf of Spain nearly a hundred kilometres of the coast belonging to the French in Senegal. A letter was read describing the departure from Buenos Ayres of M. Thouar on a new expedition to complete his work on the Pilcomayo. A note was read from M. Venukoff on the recent incidents of Russian geographical exploration. M. Chaffaujon described his late explorations in the basin of the Orinoco, to which we have already made frequent reference.

THE current number of Petermann's Mittheilungen has for its first article a lengthy communication by Dr. Theodor Fischer on the development of coasts. His conclusion is as follows:Wherever the sea by breakers and currents has exercised a preponderating influence on the form and development of coasts, whether flat or precipitous, the line of coast takes the form of a succession of arcs, in the case of steep coasts with a short, and of flat coasts with a long, radius ; where the coasts exhibit other features than these, although the action of the sea be not wholly excluded, yet other causes, especially tectonic alterations in the surface and movements of the earth's crust, are more powerful or are very recent. Herr Langhaus gives a map of the Cameroon Mountains, with an accompanying description, containing a short sketch of recent exploration in the region. Dr. Boas writes on the topography of Hudson's Bay and Hudson's Straits, with a map; and Herr Wichmann describes the new republic in South Africa, also with a small but remarkably clear map by Dr. Havernick. The usual geographical and critical notes and lists conclude the number.

M. Eugene Aubert has been charged by the Ministry of Public Instruction with a scientific mission to the basin of the Amazon.

\section{BEES AND OTHER HOARDING INSECTS ${ }^{1}$}

\section{Their Specialisation into Females, Males, and Workers}

IN discussing the differentiation of bees into females, males, and workers, I shall have no need to call your attention to any new discoveries in the world of wonders among those minute creatures that we have had with us for all ages, and whose life we are just now beginning faintly to understand. My illustrations will be drawn mainly from other orders, in which it will be impossible for me to make a mistake without its being readily seen by some of the general public as well as the specialists.

The limits of this paper will not permit elaborate definitions, or fine discriminations, and I have therefore to ask that you wil kindly make your own definitions, taking care to give to my words in general the narrowest sense compatible with the use to which I apply them.

From the creatures and the plants, that man has domesticated for his use, we have learned nearly all of the lessons in heredity, which we have no good reason to unlearn, and my first illustration shall be from one of these, the barn yard fowl.

If we mate a Black Spanish fowl with a Buff Cochin, and hatch out the eggs as the bees do theirs, in an incubator, till we have a hundred chicks, among these we shall find a very great diversity. Some when fully grown will be nearly, if not quite, as heavy as the Buff Cochin, and some will weigh little, if any, more than the Black Spanish. Their respective weights will probably vary between those natural to their sex in the two varieties to which their progenitors belong, but much the larger number will be very nearly half way between. And as colour is not necessarily correlated with weight, it is quite possible that the heaviest chick will be the blackest; that is to say, that he may take his colour almost entirely from one parent, and his weight and form from the other. In colour every one of the hundred chicks will, when fully grown, be in some degree distinguished from every other; and if we take colour, size and form together for our guide, there will not be one among the I Read before the Brooklyn Entomological Society, December 29, 1884 , by
Edwin A. Curley. whole number that we cannot readily distinguish from every other. Now this particular cross from the great difference in size, form and colour of the parent stock enables us to see very clearly a fact which the closest and most careful investigation shows to be a general law. It is this:

All offspring are variable by heredity. And under some circumstances the variations are wide.

Nearly every youth, who has amused himself with an aquarium, knows that he can dwarf his fish if he chooses to do so. Other things being equal, the weight of a fish depends upon the amount of food it is allowed to consume. This variability is so great among fishes, that of two as nearly alike as possible, either one may be fed so that he shall exceed a pound in weight, before the other, receiving very little food, shall turn the scale at an ounce.

Thus insufficiency of food affects the development of al organs. All breeders of animals have some knowledge of this fact as applied to their own business, and of which our fish merely affords a striking example. It is an inevitable deduction, that when the food is of the general quality which is suitable for the due nourishment of all the organs but is insufficient in amount, the stronger organs, if such there be, will take more than their share, and the weaker organs will go to the wall. From this matter of food supply we have a general law, which may be stated as follows :

Living creatures are variable from the amount and quality of their food. And among some orders the limits of this variation are wide.

It is scarcely necessary for me to go into the fact that the insects, being exposed to more extreme vicissitudes than the larger orders of animal life, are much more variable in almost every respect. It will be interesting, however, and it may be instructive in the line of our inquiry, to point out some powers of variation in sex in a very common plant, which, while they are very much greater than those of the bee, have some points of striking resemblance.

Indian corn is pictured to the unobserving mind as a plant bearing something good to eat at the side and a tassle on the top. The botanist tells us that the tassle on the top is a male plant, that at the side is a female plant or perhaps more than one, that all these are joined upon one stalk, and that the something good to eat is the product of the female plant, fertilized by the pollen of the male. All this is fact as far as it goes ; but it gives us no conception of the whole truth.

On going into the field in bloom we find that nearly all of the stalks have tassels on the top; they are male plants. In a good field we shall find perhaps half of them with reproductive females at the side, say two good ears of corn to a hill. There are, therefore, nearly twice as many perfect males as there are of perfect females. We find also that the undeveloped females are very numerous-from one to half a dozen on a stalk. And a close examination shows that the number of females that become developed is almost entirely a matter of food. Such an investigation shows also some plants bearing only a female on the stalk and some that are eittirely undeveloped in both sexes.

Thus in our field of Indian corn we have male stalks, male and female stalks, female stalks, neuter stalks. And the stalks that bear developed male and developed female individuals all have $(a)$ a male individual on the top, $(b)$ one, two, or three females at the side, $(c)$ one to six undeveloped females at the side, and possibly with, possibly instead of these $(c)$ they may have $(d)$ one to half a dozen buds and germs of females at the side.

If, when the corn is ripe, we go with the farmer and gather a basketful, we shall invariably find that on each ear there are kernels less perfectly developed than others, and we shall have every reason to believe that in the basketful there are some kernels that could not reproduce, that some kernels would reproduce but would, under the most favourable circumstances, give but imperfect offspring, and that there would be a very wide range in the degrees of the imperfection of the flants produced from these imperfect kernels.

As a matter of fact, the farmer in planting, selects with care the most perfect ears, and the most perfect parts only of the ears so selected, and yet we have the males, the females, and the neuters or the undeveloped for the result as I have described them.

Indian corn is so extremely variable in this matter of sex, that careful experimenting in this direction would be likely to give most interesting results in a single lifetime. 
Having now illustrated some principles of variability, and given some idea of the extent to which it may go, under our own observation, we must deal with the question before us by way of hypothesis.

Let us suppose a primitive or typical Bee among the honeyseeking insects of early days. She is necessarily a creature having such attributes as are common to all species of bees which are her offspring, but in many respects she is very unlike our Hive Bee of to-day. We see her at a time when this typical species has already learned the wonderful lesson of thrift. She stores honey in times of plenty to provide for times of want. She is feeding her offspring from her stores. As the keen competition of life goes on, she must provide for the wants of her offspring for an ever-increasing period, and, as her powers in this respect are taxed to the utmost, her powers of reproduction are of necessity diminished; she produces some imperfect eggs, and she produces fewer eggs. Still, the vast majority of her offspring perish, either for lack of sufficient food or as prey to natural enemies before their power of self-defence are sufficiently developed for successful flight or resistance.

It is quite reasonable to suppose that the bee has been subjected to such vicissitudes as these. The exrraordinary differences in the sizes of the various living species of bees would indicate the truth of the theory of insufficient food as far as we have yet followed it. If we have a species of bee only oneeighth of an inch in length while some others are an inch and a quarter in length and stout in proportion, it will take one thousand (1000) of these Lilliputian bees to weigh as much as a single specimen of one of these largest species. Is it not most reasonable to suppose that this tremendous variation in size is chiefly due to the matter of food supply, as is the well-known fact in the very large variation we can thus make in the size of an individual fish?

Now when the food supply is so very scant that the size of the offspring is necessarily much dwarfed, evidently the weakest will die in the process of rearing; evidently also the mother-bee whose reproductive powers are the weakest as to the number of offspring, and whose maternal in tincts are the strongest, that is to say, the one that lays the fewest eggs and takes the best care of her young, will best succeed.

If any broods of young perish altogether from famine, it will be those that are so numerous as entirely to overtax the powers of the mother-bee in feeding them. Thus we gradually approach a time when the care of the mother-bee extends to a period in the life of the offspring when they appreciate and respond to her affection. The offspring are still numerous and the struggle for existence is severe. The food supply is sufficient to bring the young to that point in existence when they are capable of applying with some prospect of success the instinct, that is to say, the congenital knowledge, inherited from the mother. And as the mother-hee continues after this period to help them in their struggle for existence, they see and understand her assistance, and they necessarily respond to her affection. Here is definitely established filial love, in response to maternal affection, and it is necessary that this filial love should be established in strength even in this little insect before it is possible that the specialization under consideration shall commence. It must not be supposed that the size of these tiny creatures renders them incapable of this strong feeling-we must in this respect as in others go by the evidence of our senses and the necessities of the case. Without strong affection the whole life of these bees is quite inexplicable, while with it their conduct is the natural out come of a certain amount of intelligence applied to certain conditions of existence.

Among all creatures nursed with a mother's care, filial love grows stronger and stronger according to the capacity and cir cumstances of the offspring and the strength of that affection which calls it forth. But when the time for mating approaches the young seek other relationships and so far as it is incompatible with these does filial love decay.

But what happens if the young are by nature incapacitated for these other relationships?

Then filial love necessarily grows with the individual and strengthens with her strength.

The mating instinct may be almost or wholly lacking ; and, if wholly lacking, then all of that part of the highly nervous organization inherited from the mother that is devoted to the affections will have no other outlet than in filial love.

The common life around us, and man himself will perhaps afford us some partial illustrations of this necessary law. The best illustration outside of the insect world is one of which the facts may be easily ascertained by any person who will make the inquiry.

The breeding of mules is an important industry. The horse and the ass are capable of strong affection, but their colts seldom develope a filial love which has a controlling influence on their adult life.

But the mule, the hybrid between the male ass and the female horse, except in very rare instances, is congenitally incapable of reproducing its kind. It has more or less of the instinct for mating, but it necessarily does not have the strong sexual passion of a perfect equine animal. Its love for its mother however amounts to a master passion; it is not spasmodical, but it is intense and it continues as long as there is an opportunity of showing it. It is capable of transfer to another ubject and those who breed mules in large numbers take a useful, instructive, and amusing advantage of this fact.

When the young mules are weaned, the mothers are withdrawn from their company, and one, otherwise worthless old mare is substituted for many mothers. The poor young things turn to the good-natured old mare as to a very goddess; while she receives their worship with the equanimity of her sex, never hinting in the mildest terms that it is an idolatry that should be abated. As the dilapidated goddess herself may be depended upon for her staid qualities, it follows that her worshippers are thereby kept out of mischief. And the poor mule is not a backslider, it is always a consistent worshipper.

I have stated that filial love is absolutely necessary to the specialisation under consideration. It should be added that it mu $t$ be intense in its character and capable of replacing to a large extent the maternal instinct of the perfect creature.

From the fact that insufficiency of food would affect the growth of all organs we deduce the further fact that it would affect weak organs the most, giving those not congenitally perfect an irregular development. It follows also that if a very young animal congenitally perfect, receives for a long period only sufficient food to sustain life, the organs not vital will be more or less dwarfed in their proportions, as compared to the vital organs.

For here the law of parsimony is absolute. The vital organs must receive a certain supply, or the life perishes. The nonvital organs make no such imperative demand, and they consequently get less in proportion. And an organ that is entirely useless to the life of the individual, would under such circumstances receive no nourishment whatever; excepting only as it is correlated to the organs that are useful or vital. The reproductive organs of the young of all species are entirely useless to the life of the individual ; their powers are latent, and, excepting as they are correlated to other organs, they make no demand for nourishment. Starvation must therefore dwarf the reproductive organs of very young individuals, in proportion to those which are very important, or absolutely necessary to life. In plants this fact is constantly shown all around us and our maize is a striking example.

The reproductive powers of swine are very great. But a young pig that is half-starved will not only have its reproductive powers very much retarded in their growth, it will have them diminished in their ultimate strength. This is a matter in which general observation furnishes the proof. I have not asked fishculturists the question but I am absolutely certain that, other things being equal, the number of fish-eggs will depend upon the size and thrift of the individual, and these, other things being equal, depend upon the question of food.

It is easy to imagine a possible case among the vertebrates or even the mammals in which a perfectly normal organism by long continued insufficiency of food, is allowed a slow development of those organs that are absolutely necessary for its life, and of the others most nearly correlated to these, while the organs of re production, in the incipient or undeveloped stage in which they were when starvation commenced, still remain till they become fixed and immutable, notwithstanding any abundance of food that may be given at a later period of life.

Let us now go back to the variability of eggs as shown by our hundred chicks or the variability of seeds as shown by our ears of corn. This variability is variability of the germs, and this is congenital variability. This variability as shown in the hundred chicks gives us from three to six pounds for their adult weight and they all differ in colour, form, or both.

We take no account at present of the fact that our primitive bee as shown by her offspring of to-day was far more variable 
than fowls, but we note that she was a hoarding insect, gathering with great care and industry in good times food for times of scarcity; that she supplied her young from her stores; and that they responded to her maternal cares with filial affection.

We left her at a time when the struggle for existence was keen and some of her offspring starved through no fault of her own. She was exhausted with a constant search for food and the cares of a numerous and starving family.

This necessarily involved the fact that her reproductive system was quite out of balance, she was incapable of producing as many eggs as her progenitors, and many of those that she did produce were imperfect.

Of these imperfect eggs some addled and some hatched out imperfect offspring.

At this point we proceed to inquire into the nature of the imperfections of the offspring.

There would probably be quite a variety in these defects. One might be wanting in legs, another deficient in wings, another insane, another deaf, another possibly congenitally blind, or perhaps wanting in that sense, whateverit is, by which ants and bees intelligently converse with their fellows.

All of these and many other congenital defects are possible and even probable, becatise we see them in other and the least changeable orders and species of creatures.

But the greatest in number of all the very important defects would be defects of the reproductive organs; because they are the organs in the mother which have been most affected by her unfortunate environment.

Under these circumstances, what must become of all the imperfect offspring in a sharp struggle for existence ?

Manifestly all wanting in legs, or wings, or eyes, or in any organs necessary for quick and intelligent movements in attacking or resisting enemies, or in collecting food, must die at an early age, notwithstanding any possible care of the mother.

Manifestly none of those defective in the reproductive organs would so die, unless they were also defective in some other particular, unless indeed the struggle became so keen that perfect and imperfect went to the wall together.

Manifestly also these insects thus congenitally imperfect in the reproductive organs would have a great advantage over all others in the struggle for existence, from the time at which the reproductive period in those cthers commenced.

If altogether incapable of reproduction, they would have vitality enough for themselves and a surplus to expend.

The energy inherited from the hardworking progenitors would be too great for idleness. The surplus must be expended at the dictates of love or hate. Hate, beyond that healthy indignation at attack or imposition which is necessary to self-protection, is unnatural to such beings. ${ }^{1}$ But they have one to love, and that is the mother. The perfect offspring depart to reproduce their kind, and the one, two, three, or the dozen of the imperfect ones, stay behind with the mother bee, or if she dies they transfer their affection to some one of their perfect sisters.

Now another hoard of honey must be gathered, and another lot of eggs laid, hatched out and cared for. The female bee works industriously and, true to her instinct, denies herself of necessary food that she may lay by the more for her future offspring.

And now these creatures, happy in their deprivation, capable of supplying their own wants with ease, insist on gathering food for the mother-bee. She takes it with eagerness, tastes and stores it away. And after the young are hatched out, the like attempt to feed the mother-bee results in feeding them. Thus this family have for a time a great advantage in the struggle for existence and there is a perfectly adequate motive for the conduct of the kind little creatures who minister to the wants of the mother-bee.

Still this happy family is not precisely the foundation of our modern bee-hive ; it is really too affluent for complete success.

The mother-bee, no longer overworked, ricovers her health and unfortunately lays perfect eggs ; with the help of the nursemaids she rears her young without overtaxing her powers. Her family and any others like it have very decided advantages over the old type, to which nevertheless they inevitably revert, to fall into a state of starvation as before; for, in this family, the nursemaids have, and can have, no probable successors while there is plenty to eat.

If this happens to one family of bees, it will probably happen ${ }^{I}$ Lubbock's instances of ants attacking strangers and not rescuing friends by no means demonstrates the opposite of this proposition. to many families. The temporary affluence of one family caused by the presence of the helpers will itself increase the depth of poverty in the neighbouring families, and this poverty will give them helpers in undeveloped bees in the next generation, by which in turn they will be raised to affluence. Thus there will be alternating generations of bees-that is to say, generations with helpers, followed by generations without them.

Among those that go forth from the mother-nest to find mates and rear families of their own are some that are congenitally weak in the reproductive organs. The majority of these meet with sound mates and the variation dies out. But some individuals thus congenitally imperfect meet with like mates. The congenital weakness of the reproductive organs is intensified in the offspring. The majority are perhaps so imperfect as not to be able to reproduce their kind. Any of these that reach maturity will be glad helpers of the mother-bee.

Their less imperfect brothers and sisters are defective in many degrees. The offspring of one never reach maturity. Those of another nearly all thrive and there are a dozen reproductive females among them.

In their migrations at swarming time these bees sometimes become established near less affluent families, congenitally perfect, and are sometimes crossed with them.

Here we have the bees in a condition of the greatest variability as to reproductive powers, but all of those that are getting on well in the world have among their offspring some that cannot reproduce, and helpers are consequently numerous.

About this time the paupers are established as a distinct variety. Sick and discouraged with the unsuccessful battle of life, they are more or less tolerated in the affluent families of their neighbours. But when they have recovered their bodily strength, they have not also regained their mental balance. They have become accustomed to a life of tolerated dependence ; so they live in the nest and lay eggs to be reared by their industrious neighbours. Sometimes the imposition becomes too great for good nature to stand and there may be a terrible slaughter of the innocent paupers and their offspring. The ones however that most nearly resemble the useful members of the com munity escape destruction and thus are established the CuckooBees, their simulation of virtue being ever the closer as indignation increases at their vice.

The varieties become extremely numerous; many of them however becoming rapidly extinct. At first in all families where there are helpers there are almost or perhaps quite as many undeveloped males; but this being for bees a hurtful variation the tendency of natural selection is to their diminution. On the whole those families are the most successful in which there are the largest number of undeveloped females.

All this time experience is being gathered in the mothers and differentiated and stored in their systems, to re-appear as instinct and intelligence in the offspring.

Sometimes the most affluent families come to want, and perfect females are dwarfed in their reproductive organs by scarcity of food and are only capable of being helpers.

From all this diversity there is at last a type evolved which is on the whole the best for the majority of the bees. This type is one involving a degree of imperfection in the reproductive organs of all offspring unless highly stimulating food in large quantity is supplied from a very early stage of growth. Thus the normal product is simply a helper and the number of males and females in proportion to the number of helpers and the food supply is a matter entirely under the control, not of chance nor of the mother, but of the community. 'This then, I think, is the foundation of the Hive-Bee family, the highest type of the flying Hymenoptera.

As instinct enlarges and intelligence increases, the helpers take more and more upon themselves the care of the household. They become pre-eminently the workers, and their officious interference is continually stopping the mother-bee's toil, and stuffing her with the best food they can obtain. She gives herself up more and more exclusively to the work of reproduction, and her powers increase till she becomes capable of changing food into eggs and individually starting a hundred thousand existences in her single lifetime.

Between this highest type of the bee and the lowest, we find several hundred varieties all capable of explanation, either as progressive or retrogressive developments from our primitive bee. Many of them are highly specialised in their social habits, and it seems to me that all those that have two fully developed sexes and one or more undeveloped sexes, must necessarily have 
thrift, intelligence and filial love as the foundation without which it is impossible that such creatures should of themselves build up such a singular condition.

It seems to me that hunger, something approaching starvation, is necessary as a beginning of the specialisation. Now we all know that from their capacity to increase with enormous rapidity some insects are subject to great vicissitudes in the matter of food. The locusts, for instance, increase in numbers till, having eaten everything in their native habitat, they leave it in dense masses that obscure the heavens and which devastate vast regions. Of the next brood, immensely more vast in numbers than even these, comparatively a small remnant reach maturity, and scarcely any reproduce their kind. The race grows up again from the few starved individuals too weak to leave the old habitat and of which a few manage to survive long enough to lay some eggs. Those doubtless produce many imperfect insects, but these specialisations are not useful to the race in this caee, and they cannot survive. I think it likely, however, that man could specialise locusts and many other insects in this way without difficulty. I think it likely that he could with great care so specialise fish and possibly fowls and with great patience and much difficulty some of the mammals. I think also that if mules were from a thrifty hoarding stock like squirrels they would be in the habit of feeding the old mare as the worker feed the mother-bee. But while it may be allowable to mention these as interesting possibilities I do not propose to discuss them in this paper.

There is another element which is, I think, very important in fixing the definite type of the workers, and which I had intended to discuss. But while I think that element important in the bee and perhaps absolutely necessary for the still higher specialisation of the ant, I think also that a permanent body of workers is necessarily evolved from the conditions which I have assumed a natural and proper to the primitive bee.

To recapitulate in few words :

I presuppose a primitive bee fertile and affectionate, hoarding and intelligent.

I show that great want will necessarily diminish the number of her eggs.

That it will render some eggs imperfect by deranging the reproluctive organs of the mother.

That consequently some of the offspring will be defective in the reproducing organs.

That while other imperfect bees will generally die before maturity, those imperfect only in the reproductive organs will live if the perfect offspring live.

That some of these being incapable of mating, will not go away for that purpose, but will stay with the mother-bee.

That, having surplus energy to expend, they will use it in accordance with the instinct of the race in gathering and storing food.

That the surplus food will be utilised by the mother-bee, and that therefore this family will be affluent.

That, being affluent, the formerly overtaxed mother will recover her health, and that her offspring will thereafter be perfect.

That consequently these nursemaid-bees will have no suscessors, and the family will therefore be again reduced to want.

That some bees of the same hatch with the nursemaids will be congenitally imperfect, notwithstanding that they leave the mother and find mates.

That the offspring of congenitally imperfect bees will be extremely variable.

That some of this offspring will be unable to reproduce and that they will remain with the mother-bee as nursemaids or helpers.

That these helpers from the congenital imperfections of their mothers will have successors; substantially as is seen among the hive-bees and the humble bees of the present day, and

That the variation thus started will eventually be reduced to a definity type or to definite types-by the survival of the fittest.

That whatever other circumstances may aid in producing the result in question, this is sufficient of itself to account for the specialisation of the bee and the ant into females, males and workers.

SCIENCE IN FRENCH COCHIN CHINA

$W E$ have already referred to an official publication of the French Colonial Government in Saigon, entitled Excur sions et Reconnaissances, which appears every two months, and is wholly devoted to recording the investigations made by French officials in French Cochin China and the neighbouring semiindependent and independent States. The course and results of the numerous scientific missions despatched to these regions by the Ministers of Education and the Colonies, as well as the travels and researches of private individuals, are published in this periodical; and as there are six numbers published annually, of about 200 large octavo pages each, it will readily be perceived, apart altogether from the dearth of information, other than political, with regard to the great Indo-Chinese peninsula, that these volumes form a mine of knowledge of the most authentic and trustworthy description, for the writers are for the most part men who have been specially selected in France to study the subjects with which they deal. Unfortunately, however, the publication is but little known in thi; country, no copy being obtainable in some of our largest official libraries. As it is on sale in Saigon, and doubtless also in Paris, there is no reason why a periodical so valuable should not be made accessible to English students.

We have before us the three last numbers, and from them it is possible to obtain an idea of the scientific work which the French are performing in their new possessions. No department of research escapes their attention, and they are indefatigable in studying the country and people for whose welfare they have now become responsible. In one respect these volumes resemble those of many learned societies in India and elsewhere : they are extremely varied in their contents. Shafts have been driven in all directions, and the result is here; but when we recollect the short period that the French have been even at Saigon, the still shorter period that they have been able to travel in the interior, it will be apparent that no merely private society could accomplish the work done here. The traveller in most parts of Cochin China still requires a guard of twenty or thirty tirailleurs, which can only be provided by the Government. Again, few private persons, however enthusiastic, could afford to spend several years travelling over every part of Cochin China in search of ancient inscriptions, as M. Aymonier has done. Such work as this could, under the circumstances, only be performed with the assistance of Government; and it is greatly to the credit of the French Government that amongst its responsibilities in connection with colonies in the East, it recognises that of thoroughly investigating in a scientific manne the people and territories around them. It has often been said that the French are more sympathetic rulers of subject races than the English, and that they succeed sooner in gaining their affection; whether this be true or not, it is certain that they go the right way to rule properly, by setting themselves at the outset to comprehend what manner of people and of country it is that they are called upon to rule. Science, at any rate, gains by the French practice a consideration which is not very often present to the minds of our colonial rulers.

Geography naturally plays a considerable part in the Exour sions et Reconnoissances, for a great part of Cochin China is still a terra incogrnita. For a like reason there is much that is specially ethnological. Thus, in the numbers before us we have two papers on the Moïs tribes : one by $M$. Nouet, recounting a journey amongst the Mois on the north-eastern frontier; the other, by M. Humann, on the independent Moïs. In the first these curious people are described as slothful and careless, knowing nothing of money, wandering about from place to place in search of subsistence, without any industry beyond producing articles which are absolutely necessary, and always hungry. They are excessively timid, flying into the forest on the approach of a stranger; they have no writing, and appear to have no religion either; they bury and burn the deal, but there are no subsequent ceremonies in connection with the departed. Even those within French territory lead a savage life; their existence is described as, not dying of hunger, rather than positive living. But the race is disappearing slowly from misery and disease ; the prohibition against burning the forests is siid to bear hardly on them, as it is the only method they linow for clearing patches for the cultivation of their rice. The independent tribes, described by M. Humann, are braver than those which are found further south; they can work in iron, and appear more provident and less nomadic. But they live amongst the mountains, whither they have fled before the Annamites on one side and the Siamese on the other.

Dr. Tirant contributes a very long paper, extending over the last three numbers, on the reptiles of Cochin China and Cambodia. It does not profess to be complete, for an exhaustive study of the subject would require collections and books not to 